Tohoku J. exp. Med., 1968, 96, 191-198

\title{
Liver Kynureninase Activity of an Infant with Infantile Spasm*
}

\author{
Yoshimasa Yokoyama, Keiya Tada, Toshio Yoshida, \\ Hiroshi Nakagawa and Tsuneo Arakawa \\ Department of Pediatrics (Prof. Ts. Arakawa), \\ Faculty of Medicine, Tohoku University, Sendai
}

\begin{abstract}
Paper chromatographic examination on urinary tryptophan metabolites following an oral dose of L-tryptophan, $100 \mathrm{mg} / \mathrm{kg}$, was carried out on infants and children with convulsive disorders including infantile spasm.

The incidence in cases with abnormal tryptophan metabolism was found to be higher in cases with convulsion than in those without convulsion.

A detailed study on an infant with typical infantile spasm revealed that there was a marked increase in urinary excretion of kynurenine, kynurenic acid and xanthurenic acid following the oral dose of tryptophan, and that the glutamic oxaloacetic transaminase activity of erythrocytes, vitamin $B_{6}$ levels of serum, and the kynureninase activity of the liver were within normal limits. From the present finding it was assumed that the abnormality in tryptophan metabolism observed in some cases with convulsive disorders might not be a cause of convulsion, but a sequential phenomenon associated with convulsion.
\end{abstract}

In 1959, Cochrane ${ }^{1}$ firstly reported that an increased excretion of xanthurenic acid (XA) following an oral load of tryptophan was observed in patients of infantile spasm. Since then similar findings were reported by many authors, ${ }^{2-7}$ although increased excretion of xanthurenic acid was varying from 20 to $60 \%$ in incidence according to authors.

It has been well known that an increased urinary output of xanthurenic acid following a tryptophan load is an evidence for vitamin $B_{6}$ deficiency in both animals ${ }^{8-10}$ and human beings. ${ }^{11}$ Therefore, vitamin $B_{6}$ deficiency was considered as a possible cause of certain convulsive disorders in infants and children. ${ }^{4}$ Bengt et al., ${ }^{12}$ however, reported that there was no significant difference in plasma levels of pyridoxal phosphate between patients with infantile spasms and normal children.

At the present time the reason why the disturbed tryptophan metabolism develops frequently in patients with infantile spasms remains unsolved.

This paper will describe the results of tryptophan loading test carried out on infants and children with convulsive disorders including infantile spasms, and of

Received for publication, June 15, 1968.

* Study on tryptophan metabolism in infants and children with convulsive disorders,

Part 1. 
estimation of kynureninase activity of the liver obtained from a patient with infantile spasm.

\section{Materials and Methods}

Ten cases of infantile spasms, 12 cases of convulsions of other types, 17 cases of mental retardation not associated with convulsion, and 11 healthy infants and children, were subjected to tryptophan loading test. In addition 17 cases of cerebral palsy with or without convulsion were selected randomly from an institution for mental retardation and subjected to quantitative estimation of xanthurenic acid in 8-hour urine following tryptophan loading.

Tryptophan loading test: Twenty-four-hour urine specimens were collected after Ltryptophan, $100 \mathrm{mg} / \mathrm{kg}$, was administered orally and were subjected to the two-dimensional paper chromatography using mixture consisting of n-buthanol: acetic acid: water (4:1:5 in volume) for the first direction and $20 \% \mathrm{KCl}$ solution for the second direction. Spots of tryptophan metabolites on the chromatograms were examined for fluorescence under the ultra-violet light, then were stained with the Van Urk reagent ${ }^{80}$ (p-dimethylaminobenzaldehyde in hydrochloric acid-ethanol).

Quantitative determination of xanthurenic acid was performed hy Glazer et al.'s method, ${ }^{13}$ and that of kynurenic acid and kynurenine by 0 'Brien and Ibott's method. ${ }^{14}$

Serum vitamin $B_{6}$ levels were estimated microbiologically. ${ }^{15}$ Estimation of kynureninase activity was performed according to $\mathrm{Knox}^{\prime} \mathrm{s}$ method $^{18}$ on liver specimens obtained surgically from the patient (M.U.) with infantile spasm and from four patients free from hepatic disorder and convulsions.

\section{Report of Case}

Case M.U. A one-year-6-month-old girl with infantile spasm. She had severe asphyxia soon after delivery by cesarean section at full term. There was otherwise no eventful history in neonatal period. When 10 months old, she had the first episode of tonic convulsion. Thereafter, the convulsion increased in frequency and changed to massive myoclonic jerk in type. On admission to our clinic when 1 year 6 months old, she was severely retarded in mental development.

Routine examinations of blood, urine, cerebrospinal fluid and chemical constituents in serum revealed no abnormality. Electroencephalogram revealed a typical pattern of hypsarhythmia. Two-dimensional thin layer chromatography of urinary amino acid showed a normal pattern. Serum amino acid pattern determined by an automatic amino acid analyzer was found to be within normal limits.

\section{Results}

The results of tryptophan load test were summerized in Tables 1-4.

Table 2 showed that, out of 10 cases of infantile spasms, an abnormal increase in urinary excretion was found in 3 cases for xanthurenic acid, in 4 cases for kynurenic acid, in 7 cases for kynurenine, and 4 cases for 3-hydroxykynurenine.

Table 3 showed that, out of 12 cases of grand mal epilepsy, an abnormal increase in urinary output was found in one case for xanthurenic acid, in 3 cases for kynurenic acid, in 6 cases for kynurenine and in 6 cases for 3-hydroxykynurenine.

Table 4 showed that, out of 15 cases of mental retardation not associated with 
TABLE 1. Paperchromatographic pattern of urinary excretion of tryptophan metabolites following an oral dose of L-tryptophan $(100 \mathrm{mg} / \mathrm{kg})$ in normal children

\begin{tabular}{l|c|c|c|c|c|c|c|c|c}
\hline \multirow{2}{*}{ Name } & \multirow{2}{*}{$\begin{array}{c}\text { Age } \\
\text { (y.m.) }\end{array}$} & \multicolumn{7}{c}{ Tryptophan metabolites } \\
\cline { 3 - 9 } & Try & K & AcK & KA & AA & OHK & XA & IAA \\
\hline O. A. & $\mathbf{0 . 3}$ & - & - & - & \pm & - & - & \pm & - \\
N. F. & $\mathbf{1 . 3}$ & - & - & - & - & - & - & - & - \\
H.M. & $\mathbf{5 . 1}$ & - & + & + & + & - & - & + & + \\
A. Y. & $\mathbf{5 . 8}$ & - & - & - & - & - & - & \pm & - \\
O. A. & $\mathbf{9 . 4}$ & - & \pm & - & + & - & - & $\#$ & - \\
K.T. & 9.10 & - & - & - & \pm & - & - & \pm & \pm \\
K.Y. & $\mathbf{7 . 0}$ & - & - & - & \pm & - & - & \pm & - \\
T. Y. & 9.11 & - & + & - & + & - & - & + & - \\
K.K. & $\mathbf{1 0 . 1 0}$ & - & - & - & - & - & - & \pm & - \\
O. T. & $\mathbf{1 1 . 9}$ & - & \pm & - & \pm & - & - & + & \# \\
S. S. & $\mathbf{1 2 . 0}$ & - & - & - & \pm & - & - & - & - \\
\end{tabular}

Try, tryptophan; K, kynurenine; AcK, N-acetyl kynurenine; KA, kynurenic acid; AA, anthranilic acid; OHK, 3-hydroxykynurenine; XA, xanthurenic acid; IAA, indole acetic acid.

TABLE 2. Paperchromatographic pattern of urinary excretion of tryptophan metabolites following an oral dose of L-tryptophan, $100 \mathrm{mg} / \mathrm{kg}$, in infants with infantile spasm

\begin{tabular}{|c|c|c|c|c|c|c|c|c|c|}
\hline \multirow{2}{*}{ Name } & \multirow{2}{*}{$\begin{array}{c}\text { Age } \\
\text { (y.m.) }\end{array}$} & \multicolumn{8}{|c|}{ Tryptophan metabolites } \\
\hline & & Try* & $\mathbf{K}$ & $\mathrm{AcK}$ & $\mathbf{K A}$ & $\mathbf{A A}$ & OHK & $\mathbf{X A}$ & IAA \\
\hline Y. J. & 0.9 & + & 曲 & H & H & - & - & + & - \\
\hline Y.T. & 1.5 & - & 世 & - & H & - & + & 世 & - \\
\hline o. $\mathrm{I}$. & 1.0 & H & 世 & - & \pm & - & - & 世 & - \\
\hline O.K. & 0.7 & \# & H & - & + & - & - & $H$ & - \\
\hline K.K. & 0.5 & + & $H$ & - & + & - & - & H & + \\
\hline & 3.8 & + & 册 & - & + & - & + & + & + \\
\hline S. J. & 2.9 & \pm & + & H & 册 & - & - & + & - \\
\hline K.T. & 2.11 & - & m & - & \pm & + & + & + & - \\
\hline S. N. & 3.0 & \pm & 册 & - & + & - & - & H & - \\
\hline K.T. & 4.10 & - & 曲 & - & H & - & 册 & 世 & + \\
\hline
\end{tabular}

* Cf. notes of Table 1 .

convulsion, an abnormal increase in urinary excretion was found in 4 cases of kynurenic aeid but in none for xanthurenie acid, kynurenine and 3-hydroxykynurenine.

Seventeen patients with cerebral palsy hospitalized in an institution for mental retardation were divided in two groups according to the presence or absence of convulsions, and urinary output of xanthurenic acid was determined on 8-hour urine specimens following the test dose (cf. Fig. 1). Fig. 1 revealed that average values of xanthurenic acid for patients with and without convulsions were $1.70 \pm$ $0.90 \mu$ moles $/ \mathrm{kg} / 8$ hours and $0.80 \pm 0.39 \mu$ moles $/ \mathrm{kg} / 8$ hours, respectively, the difference being statistically significant at $2 \%$ level.

A marked increase in urinary excretion of xanthurenic acid, kynurenic acid and kynurenine was found in Case M.U. (cf. Table 5). 
TABLE 3. Paperchromatographic pattern of urinary excretion of tryptophan metabolites following an oral dose of L-tryptophan, $100 \mathrm{mg} / \mathrm{kg}$, in infants and children with epilepsy other than infantile spasm

\begin{tabular}{|c|c|c|c|c|c|c|c|c|c|c|}
\hline \multirow{2}{*}{ Name } & \multirow{2}{*}{$\underset{(\text { y.m. }}{\text { Age }}$} & \multicolumn{8}{|c|}{ Tryptophan metabolites } & \multirow{2}{*}{$\begin{array}{c}\text { Types of } \\
\text { convul- } \\
\text { sion }\end{array}$} \\
\hline & & Try & $\mathbf{K}$ & AcK & $\mathbf{K A}$ & AA & $3 \mathrm{HK}$ & $\mathbf{X A}$ & IAA & \\
\hline A. $\mathbf{S}$. & 1.10 & - & + & + & + & - & - & + & + & GM* \\
\hline N.H. & 1.11 & - & $\mathrm{Wt}$ & H & \# & - & H & H & H & GM PI \\
\hline I. $\mathbf{K}$. & 0. & + & $H$ & - & \pm & - & \# & $H$ & - & GM \\
\hline T. T. & 3.5 & H & H & - & + & - & - & H & + & GM \\
\hline O. H. & 2. & - & \# & - & \pm & - & - & H & - & GM \\
\hline U. E. & 13.9 & - & W & \# & \pm & - & + & \pm & - & GM \\
\hline M.M. & 8.9 & + & 曲 & \pm & H & - & - & \# & - & GMPsy \\
\hline M.Y. & 5.1 & + & \pm & - & \pm & - & \# & \pm & - & GM \\
\hline N. S. & 11.11 & \pm & \# & \# & $H$ & - & + & H & - & GM \\
\hline K. T. & 4.7 & - & \# & \# & + & - & + & \pm & - & GM \\
\hline I. Y. & 9.4 & - & \pm & - & \pm & - & - & \pm & - & GM \\
\hline N.N. & $8^{\circ} 7$ & \pm & \pm & - & + & - & - & + & - & GMPM \\
\hline
\end{tabular}

* GM, grand mal epilepsy; **PM, petit mal epilepys; ***Psy, psychomotor epilepsy.

TABLE 4. Paperchromatographic pattern of urinary excretion of tryptophan metabolites following an oral dose of L-tryptophan, $100 \mathrm{mg} / \mathrm{kg}$, in infants and children with central nervous system disorders without convulsion

\begin{tabular}{|c|c|c|c|c|c|c|c|c|c|}
\hline \multirow{2}{*}{ Name } & \multirow{2}{*}{$\underset{(\text { y.m. }}{\text { Age }}$} & \multicolumn{8}{|c|}{ Tryptophan metabolites } \\
\hline & & Try & $\mathbf{K}$ & AcK & KA & $\mathbf{A A}$ & 3HK & $\mathbf{X A}$ & IAA \\
\hline A. $\mathrm{K}$. & 0.2 & - & + & \pm & \pm & - & - & + & - \\
\hline N. Y. & 4.0 & \pm & \pm & - & 世 & - & - & + & - \\
\hline H.W. & 2.9 & \pm & \pm & \pm & \pm & - & - & + & \# \\
\hline T. Y. & 1.4 & + & \pm & + & $\pi$ & + & - & + & $\#$ \\
\hline M. A. & 1.4 & + & - & - & - & - & - & \pm & - \\
\hline W.H. & 2.10 & + & \# & + & \# & - & - & \# & - \\
\hline K. H. & 0.7 & - & - & - & \pm & - & - & + & - \\
\hline S. Y. & 9.3 & \# & \# & - & $\pi$ & $\dot{-}$ & - & H & - \\
\hline T. T. & 0.8 & \# & - & - & \pm & + & - & + & + \\
\hline K. S. & 2.10 & - & H & - & \pm & - & - & + & + \\
\hline M. T. & 3.3 & - & \pm & + & - & - & - & - & + \\
\hline S. K. & 3.4 & - & + & - & - & - & - & \pm & - \\
\hline 0. 0 . & 8.7 & H & + & - & \pm & - & - & \pm & - \\
\hline O. Y. & 5.1 & \pm & \pm & - & - & - & - & + & - \\
\hline I. H. & 0.7 & + & + & - & - & - & - & + & - \\
\hline
\end{tabular}

TABLE 5. Urinary excretion of tryptophan metabolites after an oral dose of L-tryptophan, $100 \mathrm{mg} / \mathrm{kg}$,

in a patient M.U.

\begin{tabular}{|c|c|}
\hline $\begin{array}{l}\text { The patient of infantile spasm } \\
\text { (Case M.U.) } \\
\text { ( } \mu \text { moles } / \mathrm{kg} / \mathbf{2 4} \text { hours) }\end{array}$ & $\begin{array}{c}\text { Normal range }{ }^{81} \\
(\mu \text { moles } / \mathrm{kg} / 24 \text { hours })\end{array}$ \\
\hline $\begin{array}{lr}\text { Kynurenine } & 15.0 \\
\text { Kynurenic acid } & 19.1 \\
\text { Xanthurenic acid } & 9.9\end{array}$ & $\begin{array}{l}3-8 \\
3-5 \\
1-3\end{array}$ \\
\hline
\end{tabular}




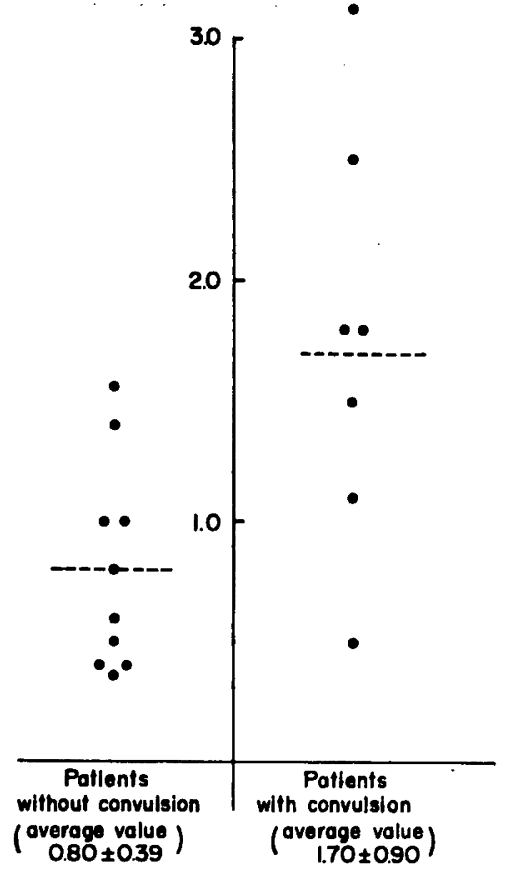

Fig. 1. Xanthurenic acid excretion ( $\mu$ moles $/ \mathrm{kg}$ ) in 8-hour urine following an oral load of L-tryptophan, $100 \mathrm{mg} / \mathrm{kg}$, in children with cerebral palsy.

TABLE 6. Glutamic oxaloacetic transaminase (GOT) in erythrocytes

\begin{tabular}{c|c}
\hline Subjects & $\begin{array}{c}\text { GOT in erythrocytes } \\
\text { (Karmen units/mg of } \mathbf{H b} \text { ) }\end{array}$ \\
\hline Case M.U. & 7.74 \\
Controls & \\
1 & 6.82 \\
2 & 7.92 \\
3 & 6.68 \\
4 & 7.43
\end{tabular}

TABLE 7. Vitamin $B_{8}$ levels in serum

\begin{tabular}{c|c|c}
\hline \multirow{2}{*}{ Subjects } & \multicolumn{2}{|c}{ Vitamin $\mathrm{B}_{\mathrm{b}}$ in serum $(\mathrm{m} \gamma / \mathrm{ml})$} \\
\cline { 2 - 3 } & Free form & Bound form \\
\hline Case M.U. & 3.2 & 2.1 \\
Controls & & \\
1 & 3.2 & 7.9 \\
2 & 2.8 & 3.3 \\
3 & 2.3 & 1.6 \\
4 & 4.2 & 4.5
\end{tabular}


TaBLE 8. Kynureninase activity in the liver

\begin{tabular}{c|c|c}
\hline Subjects & $\begin{array}{c}\text { Concentration of } \\
\text { pyridoxal phosphate } \\
\text { added to the sytem } \\
(\mu \text { moles })\end{array}$ & $\begin{array}{c}\text { Kynureninase activity } \\
(\mathrm{m} \mu \text { moles/mg protein/hr) }\end{array}$ \\
\hline Case M.U. & 0 & 35 \\
Controls & 0.05 & 46 \\
1 & 0 & 23 \\
2 & 0.05 & 33 \\
& 0 & 33 \\
3 & 0.05 & 45 \\
& 0 & 40 \\
& 0.05 & 43 \\
& 0 & 35 \\
& 0.05 & 40
\end{tabular}

The glutamic oxaloacetic transaminase activity (GOT), which was thought to be parallel to the amount of pyridoxal phosphate in erythrocytes, ${ }^{19}$ was determined by Karmen's method, ${ }^{23}$ and was found to be normal in Case M.U. (cf. Table 6). Furthermore the serum vitamin $B_{6}$ content of Case M.U. was found to be within the normal range (cf. Table 8).

The kynureninase activity of the liver was determined with and without addition of pyridoxal phosphate to the assay system, and the result showed no difference in the activity between Case M.U. and controls (cf. Table 9).

\section{Comments}

From Tables 1-3 it was clearly seen that cases with abnormality in tryptophan metabolism were encountered more frequently in infantile spasms than in convulsive disorders of other types. In this respect, our results were in good accordance with those reported by Hughes et al. ${ }^{19}$ Furthermore, as shown in Fig. 1, there was a significant increase in urinary output of xanthurenic acid following the tryptophan load in patients with convulsions than in patients without convulsions.

These findings suggested that the abnormality of tryptophan metabolism was not specific for infantile spasm, and that the metabolic disturbance was closely related to the presence or absence of convulsion of any type.

The next question remains to be solved whether the abnormality of tryptophan metabolism may be a direct cause leading to convulsions or a sequential event of convulsions. In this respect, no conclusive reports have been available so far.

Two inborn errors of metabolism involving the process of kynureninase have been reported; vitamin $\mathbf{B}_{6}$ dependent xanthurenic aciduria, ${ }^{20,21}$ and hydroxykynureninuria. ${ }^{22}$ In the patients with these disorders, it may be worthy to note that xanthurenic acid, kynurenic acid, kynurenine and 3-hydroxykynurenine were excreted in urine in larger amounts than those observed in Case M.U., and that the patients with these particular disorders showed mental retardation but had no history of convulsions. Therefore, we assumed that the abnormality of tryptophan 
metabolism was not responsible for occurrence of convulsions, and that the disturbance in tryptophan metabolism might develop as a sequential phenomenon associated with convulsions.

Then, a further question may concern with the mechanism through which convulsions cause the derangement of tryptophan metabolism.

The results of our present study revealed that in Case M.U., which was that of an infant with typical infantile spasm who excreted abnormally large amounts of xanthurenic acid, kynurenic acid, kynurenine and 3-hydroxykynurenine following an oral dose of tryptophan, the kynureninase activity of the liver, glutamic oxaloacetic transaminase activity of erythrocytes and vitamin $B_{6}$ levels of serum were within normal limits.

These findings indicated that an increased excretion of the tryptophan metabolites in Case M.U. was not due to vitamin $B_{6}$ deficiency, vitamin $B_{6}$ dependency, nor a decreased activity of kynureninase in the liver.

Hence, for a plausible explanation of an increased urinary excretion of tryptophan metabolites in Case M.U. and in patients with convulsions, such a possibility has been considered that an increase in the tryptophan pyrrolase activity may be induced by any stress such as convulsive seizures. Our experimental data dealing with this point will be reported in a next paper of ours.

\section{References}

1) Cochrane, W.A. The syndrome of infantile spasms and progressive mental retardation related to amino acid and pyridoxine metabolism. International Congress of Pediatrics (Montreal), 1959, p. 18.

2) Jaune, M., Cotte, J., Hermier, M., Yasse, L. \& Leriche, L. L'épreuve de charge au tryptophan comme moyen de détection des apyridoxinoses chez l'enfant. Pédiatrie, $1959,14,853-862$.

3) Segni, G. \& Guandullia, E. La prova del carico di triptophano nella prima infanzia. Minerva Pediat., 1962, 14, 1095-1102.

4) Bower, B.D. The tryptophan load test in the syndrome of infantile spasms with oligophrenia. Proc. roy. Soc. Med., 1961, 54, 540-544.

5) Hellström, B. \& Vassella, F. Tryptophan metabolism in infantile spasm. Acta paediat. (Uppsala), 1962, 51, 665-673.

6) Bower, B.D. \& Hughes, P.A. The significance of the tryptophan load test in infantile spasms with oligophrenia. Proc. Ass. clin. Biochem., 1961, 1, 72-79.

7) Carredu, P. Veränderungen des Tryptophanstoffwechsels bei den Blitz-Nick-SalaamKrämpfen des Kindesalters. Helv. paediat. Acta, 1963, 18, 398-407.

8) Cartwright, G.E., Wintrobe, M.M., Jones, P., Lanritsen, M. \& Haurphrey, S. Tryptophan derivatives in the urine of pyridoxine deficient swine. Bull. Hopkins Hosp., 1944, 75, 35-47.

9) Miller, E.C. \& Baumann, C.A. Relative effects of casein and tryptophan on the health and xanthurenic acid excretion of pyridoxine deficient mice. J. biol. Chem., 1945, 157, 551-562.

10) Axelrod, H.E., Morgan, A.F. \& Lepkovsky, S. The fate of tryptophan in pyridoxinedeficient and normal dogs. J. biol. Chem., 1945, 160, 155-164.

11) Greenberg, L.D. Xanthurenic acid excretion in the human subject on a pyridoxine deficient diet. Arch. Biochem., 1949, 21, 237-239.

12) Bengt, H., Arne, H. \& Olle, H. Tryptophan load test and pyridoxal-5-phosphate levels in epileptic children. Acta paediat. scand., 1966, 55, 363-384. 
13) Glazer, H.S., Mueller, J.P., Thompson, C., Hawkins, V.R. \& Vitler, R.W. A study of urinary excretion of xanthurenic acid and other tryptophan metabolites in human beings with pyridoxine deficiency induced by desoxypyridoxine. Arch. Biochem., 1951, 33, 243-251.

14) O'Brien, D. \& Ibbot, F.A. Laboratory Manuel of Pediatric Micro-and-Ultramicro-Biochemical Techniques, 3rd ed., Hoeber Medical Book, New York, 1964, p. 304.

15) Fukui, S., Kishibe, T. \& Tani, $Y$. The microbiological assay of vitamin $B_{8}$. Vitamins (Jap.), 1953, 6, 436-439.

16) Knox, W.E. The relation of liver kynureninase to tryptophan metabolism in pyridoxine deficiency. Biochem. J., 1953, 53, 379-385.

17) Marsh, M.E., Greenberg, L.D. \& Rinehart, J.F. Relationship between pyridoxine ingestion and transaminase activity. J. Nutr., 1955, 56, 115-127.

18) Sass, M.D., Vorsanger, E. \& Spear, P.W. Enzyme activity as an indicator of red cell age. Clin. Chem., 1964, 10, 12-26.

19) Hughes, P.A., Bower, B.D., Reine, D.N. \& Syed, N. Metabolism of tryptophan in childhood epilepsy. Arch. Dis. Child., 1966, 41, 642-651.

20) Tada, K., Yokoyama, Y., Nakagawa, H., Yoshida, T. \& Arakawa, Ts. Vitamin Bo dependent xanthurenic aciduria. Tohoku J. exp. Med., 1967, 93, 115-124.

21) Tada, K., Yokoyama, U., Nakagawa, H., Yoshida, T. \& Arakawa, Ts. Vitamin B $_{6}$ dependent xanthurenic aciduria. Tohoku J. exp. Med., 1968, 95, 107-114.

22) Komrower, G.M., Wilson, V., Clamp, J.R. \& Westain, R.G. Hydroxykynureninuria. Arch. Dis. Child., 1964, 39, 250-256.

23) Karmen, A. A note on the spectrophotometric assay of glutamic oxaloacetic transaminase activity in human blood serum. J. clin. Invest., 1955, 34, 131-142. 